\title{
OCCURANCE OF TETRACYCLINE AND OXYTETRACYCLINE RESIDUE IN HONEY SAMPLES: DEVELOPMENT OF ANALYTICAL HPLC METHOD
}

\author{
Roya Khosrokhavar ${ }^{1 凶}$, Afshin Zarghi $^{2}$, Hassan Yazdanpanah ${ }^{3,4}$,Masoumeh Afshar-Nasab ${ }^{1,2}$ \\ ${ }^{I}$ Food and Drug Laboratory Research Center, Food and Drug Administration, MOH\&ME, Tehran, Iran \\ ${ }^{2}$ Medicinal Chemistry Dept., School of Pharmacy, Shahid Beheshti University of Medical Sciences, \\ Tehran, IR Iran \\ ${ }^{3}$ Food Safety Research Center, Shahid Beheshti University of Medical Sciences, Tehran, IR Iran \\ ${ }^{4}$ Toxicology and Pharmacology Department, School of Pharmacy, Shahid Beheshti University of Medical \\ Sciences, Tehran, IR Iran \\ 凶khosrokhavar_r@yahoo.com \\ https://doi.org/10.34302/crpifst/2021.13.1.16 \\ Article history: \\ Received: \\ 5 July 2020 \\ Accepted: \\ 14 December 2020 \\ Keywords: \\ Tetracycline (TC) \\ Oxytetracycline (OTC) \\ Honey \\ High performance liquid \\ chromatography (HPLC)

\begin{abstract}
Detection of tetracyclines (TCs) in honey samples is a worldwide concern for controlling of bacterial diseases in honeybees lead to drug resistance in pathogenic organisms and exerts to allergic or toxic reaction in humans. Therefore, it decided to develop of an efficient clean-up procedure for determining of tetracycline (TC) and oxytetracycline (OTC) residue in consuming honey samples using HPLC-UV methods with SPE cartridge as the clean-up procedure. Therefore, it decided to develop of an efficient method for determining of tetracycline (TC) and oxytetracycline (OTC) residue in consuming honey samples using HPLC-UV methods with SPE cartridge as the clean-up procedure. Mobile phase composed of phosphoric acid / acetonitrile $(78 / 22, \mathrm{v} / \mathrm{v})$ with flow rate of $1.7 \mathrm{ml} / \mathrm{min}$ and separation was done by $\mathrm{C} 18$ column at $25^{\circ} \mathrm{C}$. Overall, TC and OTC were detected in $100 \%$ of analyzed samples with a mean level of $0.43 \pm 0.47$ and $0.7 \pm 0.53$ ppm, respectively. Unfortunately, no maximum residues limit (MRL) has been fixed by some countries and international Committee especially EU in bee products which confirms the higher incidence of contamination and worried in honey products. Our data supposed that the current validated method is suitable for determining of TCs in honey in control laboratories and import-export inspection sites.
\end{abstract}

\section{Introduction}

Honey originated from the nectar of plants with different natural valuable component which are gathered, modified, stored and dehydrated by the honey bee (Wan et al. 2005). Ample of evidence indicated that residuals of antibiotic in in apiculture for treatment of bacterial disease. Tetracyclines (TCs) such as tetracycline (TC) and oxytetracyline (OTC) are commonly used to control bacterial diseases in foulbrood have been found above the regulatory standards in honey samples (Hakuta et al. 2009; Wan et al. 2005).

Existence of tetracyclines antibiotics residue in honey introduced as a central subject in monitoring of the quality and safety of honey bee (Dinkov et al. 2005; Khosrokhavar et al. 2008; Khosrokhavar et al. 2011). Consuming of honey containing with TCs resulted health implications due to drug resistance, allergic reaction, hepatotoxicity and yellow teeth (Dinkov et al. 2005; Hakuta et al. 2009). 
Furthermore, the side effects of TCs in gastrointestinal disturbance is related to the selective pressure of antibiotics on human gut microflora and bacterial resistance (Tsukamoto et al. 2009; Viñas et al. 2004). Therefore, to elusion of implicated health problems associated with TCs residue in animals feed, some countries and international Committee have set maximum residue level (MRL) for TCs in honey in different range such as Japan (0.1 ppm), United Kingdom (UK) and Switzerland (0.020.05ppm), Codex (0.1-1.2 ppm) and FAO/WHO (0-0.03 ppm). Contamination of honey samples with TC, OTC and and the other antibiotics is a global concern studied in Chine (Chen et al. 2001), india (Solomon et al. 2006), Greece (Saridaki-Papakonstadinou et al. 2006), France (Martel et al. 2006), Brazil (Granja et al. 2009) and UK (Thompson et al. 2005).

Prevalence of antibiotics in honey samples reported that 2 out of 72 samples were contaminated with tetracycline in India (Solomon et al. 2006). Another similar study in Greece and Germany showed $29 \%$ and $21 \%$ of the honey samples had tetracycline residues, respectively (Brasse 2001; SaridakiPapakonstadinou et al. 2006). The mean of residual tetracyclins level were higher than the European Commission permissible level (50 $\mu$ g.kg-1). Nevertheless, regulatory authorities have not been fixed MRLs for TCs in bee products and practically are illegal for application in bee products (Fujita K 2008; Viñas et al. 2004). Therefore, continuous assessment of bee products with TCs residue by precise and validated method is essential for regulatory authorities and organization.

Therefore, several analyzing methods are suggested to detect of TCs residue in honey product following LLE or SPE cleanup coupled with a choice of detection methods such as HPLC with UV or fluorescence detector, liquid chromatography-mass spectrometry (LC-MS) and capillary electrophoresis (Debayle et al. 2008; Jeon and Paeng 2008; Oka et al. 1987; Oka et al. 2000; Pena et al. 2005; Peres et al. 2010; Viñas et al. 2004).
Previous studies shows that clean-up of TCs were carried out by cartridge column treatments. Oka et al has used a two-dimensional clean-up and carboxylate cartridge for purifying TCs in honey sample (Oka et al. 1987; Oka et al. 2000). Pena et al. investigation show that this cartridge is not suitable in honey sample due to large variation in $\mathrm{pH}$ and they used the propylesulfonate cartridges for extraction of TCs in samples (Pena et al. 2005). Fujita et al. used McIlvaine buffer for extracting of TCs in honey samples with polymeric cartridge (PLS2) and metal chelate affinity column (MCAC) and fluorescence detector (Fujita K 2008). Munstedt et al. reported the simultaneous detection of TCs in honey after SPE following extensively processing (extraction and clean up) before the analysis (Münstedt et al. 2002). In other study, trace amount of TCs antibiotics in honey determined by sulfobetaine-type polymer resin as an SPE adsorbent in HPLC analysis (Tsukamoto et al. 2009). Moreover, CarrascoPancorbo et al. used reversed-phase highperformance liquid chromatography coupled to ultraviolet and electrospray time-of-flight mass spectrometry on-line detection for the separation of eight TCs in honey samples (CarrascoPancorbo et al. 2008).

Also, a chelating agent was added to extraction buffer due to interfering effect from minerals in honey samples as same as other previous reports (Fujita K 2008; Khosrokhavar et al. 2011; Viñas et al. 2004). Therfore, it supposed that SPE cleanup and HPLC with UVdetection (HPLC-UV) are already used to determine TC and OTC residue in honey samples as the most popular and valuable method (Hakuta et al. 2009; Peres et al. 2010). We supposed that proposed routine method provides simultaneously determining of TC and OTC residue level in honey samples collected from Iran using HPLC coupled with reversedphase SPE to examine contamination level of TCs residue in honey. The limits of detection and quantification were $0.25 \mu \mathrm{g} . \mathrm{g}-1$, respectively. The recoveries varied from 74 to $91 \%$ while the relative standard deviations 
(RSDs) were less than $11 \%$ under the intermediate precision conditions.

Unfortunately, no official maximum residue levels have been set for TCs residue detecting in honey products in Iran. Up to now, there is inadequate investigation on the TC and OTC residue in Iran which revealed that detectable level of OTC level in honey samples and probable a high risk of exposure with drug residues (Arabsorkhi and Sereshti 2018; Kalal et al. 2007; Mahmoudi et al. 2014). Therefore, the aim of present study was to investigate the occurrence of OTC and TC in honey in Iran.

\section{Materials and methods}

\subsection{Materials}

All reagents and solvents used for the experiments were analytical or HPLC grade. The TC and OTC standard were provided from Sigma-Aldrich. The separation was done using C18 column (RP- BONDAPAK C18, 250× 4.6 $\mathrm{mm}$, particle size $5 \mu \mathrm{m}$, Berlin, Germany).

\subsubsection{Samples}

The analysis was performed on 31 samples which were bought from local supermarkets. Samples were collected by trained personnel from various sales in different geography zones in Tehran, Iran and then stored at $4^{\circ} \mathrm{c}$ before analysis.

\subsubsection{Apparatus:}

TCs analysis were done by HPLC (Dionex, München, Germany) equipped with a Dionex P680 Pump (Dionex) and UV detector (Dionex UVD 170U/340U) operated at wavelength of $268 \mathrm{~nm}$. The analytical separation column was performed by $\mathrm{C} 18$ column $(250 \times 4.6 \mathrm{~mm}$, ACE C18-A3681, Dionex).The Chromeleon (version 6.60, Dionex) software was used to acquisition of data.

\subsubsection{Calibration of HPLC Standard preparation}

The mixed stock standard solutions of TC and OTC $\left(1000 \mu \mathrm{g} . \mathrm{ml}^{-1}\right)$ were prepared weekly composed of $100 \mathrm{mg}$ TC and $100 \mathrm{mg}$ OTC in $100 \mathrm{ml}$ methanol. Working standard solutions (0.25-4 $\left.\mu \mathrm{g} \cdot \mathrm{ml}^{-1}\right)$ were prepared daily before using by diluting the stock solutions with deionized water. All standard solutions wrapped with aluminum foil to prevention of TCs decomposition after light exposure (Anderson et al. 2005). The standard curve was built using five point against the AUC with higher regression coefficient $\left(r^{2}>0.998\right)$.

\subsubsection{Mobile phase preparation}

A phosphate buffer solution $(\mathrm{pH}=2.3)$ was prepared by dissolving $1.35 \mathrm{ml}$ orthophosphoric acid in $900 \mathrm{ml}$ of water, adjusting to $\mathrm{pH} 2.3$ with drop wise addition of $0.1 \mathrm{~mol} . \mathrm{L}^{-1}$ potassium hydroxide and finally making up to 1 liter with water. The optimum analysis condition obtained using phosphate buffer: acetonitrile $78: 22, \mathrm{v} / \mathrm{v}$ in isocratic elution program with a flow rate of $1.7 \mathrm{ml} / \mathrm{min}$.

\subsubsection{Extraction procedure:}

Briefly, one gram of honey samples were mixed by $5 \mathrm{ml}$ of $0.1 \mathrm{M} \mathrm{Na}$-EDTA solution $(\mathrm{pH}=4)$ and centrifuged in $8000 \mathrm{rpm}$ for $20 \mathrm{~min}$. The extract was passed through SPE cleanup column following preconditioning. The column was washed with $5 \mathrm{ml}$ ethyl acetate and was filtered by $0.45 \mu \mathrm{m}$ membrane filter and then dried by gentle stream of nitrogen. Finally, the residue was reconstituted with mobile phase and $50 \mu 1$ of the solvent was injected into the HPLC system (Fig.1).

\subsubsection{Method Validation:}

The reliability of analytical method such as extraction and cleanup efficacy was verified by evaluation of accuracy, precision and recovery by spiking at three concentrations of TC and OTC $\left(0.5,1\right.$ and $\left.4 \mu \mathrm{g} \cdot \mathrm{ml}^{-1}\right)$ by standard addition method in fortified or spiked sample. Repeatability (intra-day) and reproducibility (inter-day) was determined by three-replicated samples spiked with TC and OTC on the same day and three other different days.

The limit of detection (LOD) and limit of quantification (LOQ) were estimated for a signal-to-noise ratio of 3 and 10 , respectively with precision within $\pm 20 \%$. The method linearity was reported as $\mathrm{x}$ (TC or OTC concentration in $\mu \mathrm{g} \cdot \mathrm{g}^{-1}$ ) and $\mathrm{y}$ (Peak area of OTC or TC) with the regression coefficient $\left(\mathrm{r}^{2}\right)$ of 0.99 . 


\subsection{Statistical Analysis}

Data analysis was performed using the Excel 2007 software. $\mathrm{p}<0.05$ was considered as statistically significant in the present study.

Fig.1.Extraction procedures of honey samples
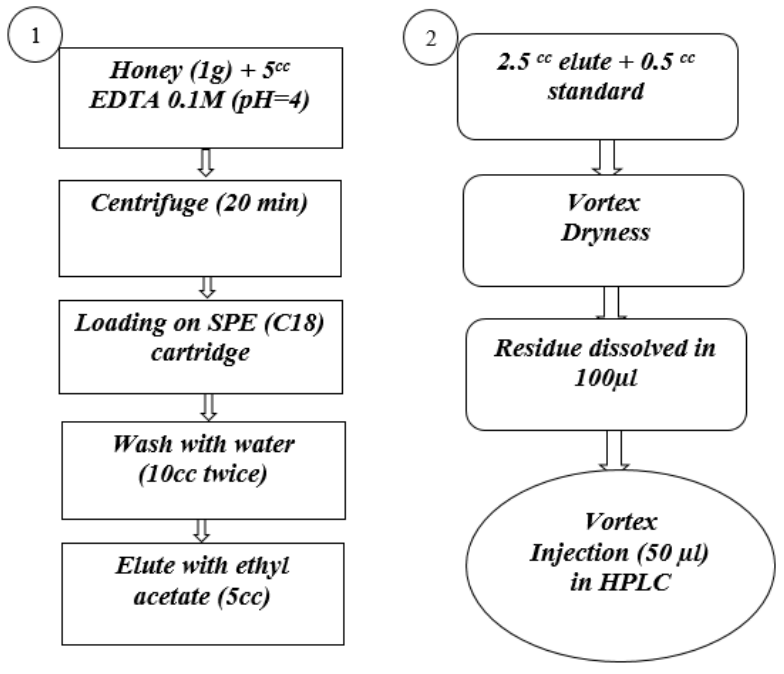

\section{Results and discussions}

TCs are used against bacteria to prevent two of the main enemies of the honeybee, streptococcus pluton in Europe and Bacillus Larvae in America, which cause food born disease; beekeepers commonly apply the widespectrum antibiotics. Although, the residue of
TCs in honey can leads to possible toxic or allergic reaction, but in many countries, no maximum residue limits (MRL) are established for TCs in honey (Pastor-Navarro et al. 2007). Besides, there are no data level of TC and OTC residue contamination in honey of Iran and many countries. Therefore, it decided to evaluate the contamination level of TCs (TC and OTC) in honeys using validated and routinely HPLC-UV method in honey samples in present study.

\subsection{Analytical method performance}

The average recovery experiments were performed at desired levels at ranged $74.4 \%$ to $92.4 \%$ for $\mathrm{TC}$ and $75.5 \%$ to $91.5 \%$ for OTC are shown in Table 1 and Table 2, to determine of accuracy in proposed method which is in agreement with the European Union regulation (2002/657/EC) (Comission 2002).

The average of recovery results confirmed the accuracy of the method. The results of precision and accuracy are presented in Table 1. Our data in precision showed that less than $11 \%$ percentage of correlation variation in three spiked levels within an acceptable range with EC recommendation (Comission 2002) similar to Giannetti et al.,2010 (Giannetti et al. 2010).

Table 1. Inter and intra-assay recoveries of TC from honey sample

\begin{tabular}{|c|c|c|}
\hline \multirow{2}{*}{$\begin{array}{c}\text { Conc. TC } \\
(\mathrm{ppm})\end{array}$} & Intraday & Interday \\
\cline { 2 - 3 } & Mean Recovery(\%) \pm SD & Mean Recovery(\%) \pm SD \\
\hline 0.5 & $80.8 \pm 6.4$ & $74.4 \pm 3.1$ \\
\hline 1 & $87.9 \pm 2.1$ & $84.4 \pm 2.9$ \\
\hline 4 & $92.4 \pm 5.9$ & $86.3 \pm 1.4$ \\
\hline
\end{tabular}

Table 2. Inter and intra-assay recoveries of OTC from honey sample

\begin{tabular}{|c|c|c|}
\hline \multirow{2}{*}{$\begin{array}{c}\text { Conc. OTC } \\
(\mathrm{ppm})\end{array}$} & Intraday & Interday \\
\cline { 2 - 3 } & Mean Recovery $(\%) \pm \mathrm{SD}$ & Mean Recovery(\%) \pm SD \\
\hline 0.5 & $77.7 \pm 10.9$ & $75.5 \pm 11.4$ \\
\hline 1 & $90.9 \pm 6.1$ & $79.0 \pm 9.1$ \\
\hline 4 & $91.5 \pm 4.1$ & $78.1 \pm 3.8$ \\
\hline
\end{tabular}


The HPLC technique with an SPE cleanup is a routine and reliable method which used in the current study to determine simultaneous of TC and OTC level in honey samples. In sample preparation stage, we used only $1 \mathrm{~g}$ of honey samples to reduce the solvents usage. Calibration curves were obtained from five spiked samples ranged from $0.25-4 \mu \mathrm{g} \cdot \mathrm{ml}^{-1}$ for TC and OTC. The linearity of calibration curve was plotted TC and OTC concentration versus AUC. Least squares linear regression analysis gave a correlation coefficient of $\mathrm{r}^{2}=0.997$ with calibration curve of $[\mathrm{Y}=1.944 \mathrm{x}+0.387]$ for OTC and correlation coefficient of $\mathrm{r}^{2}=0.999$ and a calibration curve of $[Y=4.28 \mathrm{x}+0.652]$ for $\mathrm{TC}$ was concluded. RSD for each concentration in the standard solutions was lower than $3 \%$. The LOD and LOQ of chromatographic condition were obtained for TC and OTC equal to 0.03 and $0.1 \mu \mathrm{g} \cdot \mathrm{ml}^{-1}$ for TC and OTC, respectively. Although the obtained LOQ amount is similar to the LOQ which reported previous study. The mean retention time of OTC and TC in the standard and spiked samples were 4.3 and 5.1 minutes. Although the obtained retention time is present investigation is less than the previous reports in suggested line.

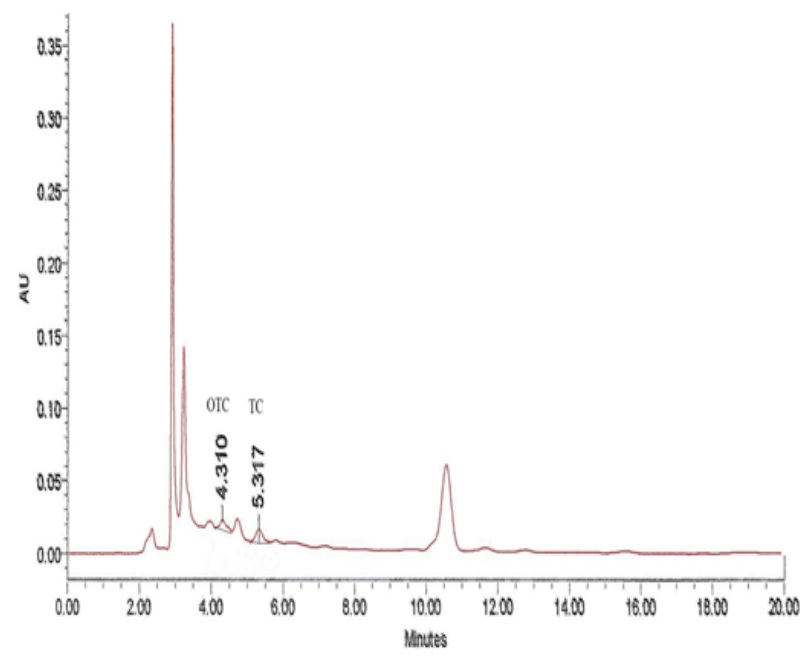

Fig.2.Chromatogram of a honey spiked with 0.5 ppm of OTC and TC

Also, specificity of method was evaluated with respect to standard addition by extracting and analyzing fortified samples. The chromatograms recorded at $268 \mathrm{~nm}$ were free of interfering peaks (Figure.2). Buffering at $\mathrm{pH}=$ 2.3 with $\mathrm{Na}_{2}$-EDTA and orthophosphoric acid caused a sharp peak for TC and OTC. The stability of the column was evaluated by calculating the retention time of a standard solution of TC and OTC every sample injections (after washing with the eluent for $20 \mathrm{~min}$ ). The stability of TC and OTC was evaluated both in spiked honey matrix and in standard solution under various storage conditions. These samples were stable at $-20^{\circ} \mathrm{C}$ even after a 40 -day storage. The selectivity of methods was determined by no significant interfering peaks in the chromatograms with other compounds.

\subsection{Incidence of TC and OTC in the honey samples}

Honey as a popular food is used with most of the people, all over the world. Results of the studied commercial honey samples are presented in Table 3. According to the results, the amount of TC and OTC residue in 31 real samples were $0.43 \pm 0.47 \mu \mathrm{g} . \mathrm{g}^{-1}$ and $0.7 \pm 0.53$ $\mu \mathrm{g} . \mathrm{g}^{-1}$ in honey samples, respectively. Our data showed that TC and OTC were detected in all of the analyzed honey samples $(100 \%)$ which has been indicated in Table.3. Furthermore, the minimum and maximum level of TC and OTC in real samples were observed between 0.032.27 and $0.02-1.95 \mu \mathrm{g} . \mathrm{g}^{-1}$, respectively. The data showed that OTC content in all samples were higher than the maximum permissible levels established by codex and Japan. But, $80.6 \%$ of honey samples was higher than the maximum permissible levels (Table 3 ).

The amount of TC, OTC and same antibiotic contaminations in homey samples were reported by the other studies. Solomon reported that $14 \%, 28 \%, 29.2 \%$ of honey samples in 2006 , 2007, 2009 were contaminated with tetracycline and same antibiotic more than the prescribed limit (Solomon et al. 2006). In Greece, 29\% of the honey samples had tetracycline-derived residues 251 which were analyzed by HPLC (Saridaki-Papakonstadinou et al. 2006). The results of Martel et al., in France revealed that tetracycline residues were detected in honey after a treatment in hives, indicating their 
permanence and spreading into the hive (Martel et al. 2006).

Other similar study in UK showed that the higher level of OTC residue levels $(3.7 \mathrm{mg} / \mathrm{kg})$ in honey after treatment of honeybee colonies after eight weeks (Thompson et al. 2005). Chen et al., were successfully separated TC, OTC, and the other antibiotics in honey samples collected in china by high performance capillary electrophoresis (Chen et al. 2001).

Table 3. TC and OTC level in real honey samples $(n=31)$

\begin{tabular}{|c|c|c|c|c|c|c|c|c|}
\hline \multirow{2}{*}{ 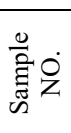 } & \multirow{2}{*}{$\begin{array}{c}\mathrm{TC} \\
(\mathrm{ppm})\end{array}$} & \multicolumn{3}{|c|}{ Higher than MRL in } & \multirow{2}{*}{$\begin{array}{l}\text { OTC } \\
(\mathrm{ppm})\end{array}$} & \multicolumn{3}{|c|}{ Higher than MRL in } \\
\hline & & $\begin{array}{c}\text { Japan } \\
(0.1 \mathrm{ppm})\end{array}$ & $\begin{array}{c}\mathrm{UK} \\
(\geq 0.02 \mathrm{ppm})\end{array}$ & $\begin{array}{c}\text { Codex } \\
(\geq 0.1 \mathrm{ppm})\end{array}$ & & $\begin{array}{c}\text { Japan } \\
(0.1 \mathrm{ppm})\end{array}$ & $\begin{array}{c}\mathrm{UK} \\
(\geq 0.02 \mathrm{ppm})\end{array}$ & $\begin{array}{c}\text { Codex } \\
(\geq 0.1 \mathrm{ppm})\end{array}$ \\
\hline 1 & 0.28 & $\mathrm{Y}$ & $\mathrm{Y}$ & $\mathrm{Y}$ & 0.39 & $\mathrm{Y}$ & $\mathrm{Y}$ & $\mathrm{Y}$ \\
\hline 2 & 0.07 & $\mathrm{~N}$ & $\mathrm{Y}$ & $\mathrm{N}$ & 0.98 & $\mathrm{Y}$ & $\mathrm{Y}$ & $\mathrm{Y}$ \\
\hline 3 & 0.22 & Y & Y & Y & 0.60 & Y & Y & Y \\
\hline 4 & 0.08 & $\mathrm{~N}$ & $\mathrm{Y}$ & $\mathrm{N}$ & 0.02 & $\mathrm{Y}$ & $\mathrm{Y}$ & $\mathrm{Y}$ \\
\hline 5 & 0.22 & $\mathrm{Y}$ & $\mathrm{Y}$ & $\mathrm{Y}$ & 0.30 & $\mathrm{Y}$ & $\mathrm{Y}$ & $\mathrm{Y}$ \\
\hline 6 & 0.40 & $\mathrm{Y}$ & $\mathrm{Y}$ & $\mathrm{Y}$ & 0.13 & $\mathrm{Y}$ & $\mathrm{Y}$ & $\mathrm{Y}$ \\
\hline 7 & 0.23 & $\mathrm{Y}$ & $\mathrm{Y}$ & $\mathrm{Y}$ & 0.56 & $\mathrm{Y}$ & $\mathrm{Y}$ & $\mathrm{Y}$ \\
\hline 8 & 0.27 & $\mathrm{Y}$ & $\mathrm{Y}$ & $\mathrm{Y}$ & 0.12 & $\mathrm{Y}$ & $\mathrm{Y}$ & $\mathrm{Y}$ \\
\hline 9 & 1.07 & Y & $\mathrm{Y}$ & Y & 0.60 & Y & Y & $\mathrm{Y}$ \\
\hline 10 & 0.30 & Y & Y & Y & 1.40 & Y & Y & Y \\
\hline 11 & 0.10 & $\mathrm{Y}$ & $\bar{Y}$ & $\bar{Y}$ & 0.35 & $\mathrm{Y}$ & $\mathrm{Y}$ & $\mathrm{Y}$ \\
\hline 12 & 0.43 & $\mathrm{Y}$ & $\mathrm{Y}$ & $\mathrm{Y}$ & 0.38 & $\mathrm{Y}$ & $\mathrm{Y}$ & $\mathrm{Y}$ \\
\hline 13 & 0.44 & $\mathrm{Y}$ & $\mathrm{Y}$ & $\mathrm{Y}$ & 0.25 & $\mathrm{Y}$ & $\mathrm{Y}$ & $\mathrm{Y}$ \\
\hline 14 & 0.05 & $\mathrm{~N}$ & $\mathrm{Y}$ & $\mathrm{N}$ & 0.78 & $\mathrm{Y}$ & $\mathrm{Y}$ & $\mathrm{Y}$ \\
\hline 15 & 0.32 & $\mathrm{Y}$ & $\mathrm{Y}$ & $\mathrm{Y}$ & 0.43 & $\mathrm{Y}$ & $\mathrm{Y}$ & $\mathrm{Y}$ \\
\hline 16 & 0.91 & $\mathrm{Y}$ & $\mathrm{Y}$ & $\mathrm{Y}$ & 0.60 & $\mathrm{Y}$ & $\mathrm{Y}$ & $\mathrm{Y}$ \\
\hline 17 & 0.36 & Y & Y & Y & 0.29 & Y & Y & Y \\
\hline 18 & 0.07 & $\mathrm{~N}$ & $\mathrm{Y}$ & $\mathrm{N}$ & 0.65 & $\mathrm{Y}$ & $\mathrm{Y}$ & $\mathrm{Y}$ \\
\hline 19 & 0.03 & $\mathrm{~N}$ & $\bar{Y}$ & $\mathrm{~N}$ & 0.03 & $\mathrm{Y}$ & $\mathrm{Y}$ & $\mathrm{Y}$ \\
\hline 20 & 1.35 & $\mathrm{Y}$ & $\mathrm{Y}$ & $\mathrm{Y}$ & 0.76 & $\mathrm{Y}$ & $\mathrm{Y}$ & $\mathrm{Y}$ \\
\hline 21 & 0.40 & $\mathrm{Y}$ & $\mathrm{Y}$ & $Y$ & 1.37 & $\mathrm{Y}$ & $\mathrm{Y}$ & $\mathrm{Y}$ \\
\hline 22 & 0.28 & $\mathrm{Y}$ & $Y$ & $\mathrm{Y}$ & 1.95 & $\mathrm{Y}$ & $\mathrm{Y}$ & $\mathrm{Y}$ \\
\hline 23 & 0.12 & $\mathrm{Y}$ & $Y$ & $Y$ & 0.77 & $\mathrm{Y}$ & $Y$ & $\mathrm{Y}$ \\
\hline 24 & 0.36 & $\mathrm{Y}$ & $Y$ & $\mathrm{Y}$ & 0.25 & $\mathrm{Y}$ & $\mathrm{Y}$ & $Y$ \\
\hline 25 & 0.04 & $\mathrm{~N}$ & $\mathrm{Y}$ & $\mathrm{N}$ & 1.60 & $\mathrm{Y}$ & $\mathrm{Y}$ & $\mathrm{Y}$ \\
\hline 26 & 1.07 & $\mathrm{Y}$ & $\mathrm{Y}$ & $\mathrm{Y}$ & 1.92 & $\mathrm{Y}$ & $\mathrm{Y}$ & $\mathrm{Y}$ \\
\hline 27 & 0.51 & $\mathrm{Y}$ & $\mathrm{Y}$ & $\mathrm{Y}$ & 0.66 & $\mathrm{Y}$ & $\mathrm{Y}$ & $\mathrm{Y}$ \\
\hline 28 & 0.26 & Y & $\mathrm{Y}$ & Y & 1.08 & Y & Y & Y \\
\hline 29 & 2.27 & $\mathrm{Y}$ & $\bar{Y}$ & $\mathrm{Y}$ & 0.83 & Y & $\bar{Y}$ & $\mathrm{Y}$ \\
\hline 30 & 0.33 & $\mathrm{Y}$ & $\mathrm{Y}$ & $\mathrm{Y}$ & 1.29 & $\mathrm{Y}$ & $\mathrm{Y}$ & $\mathrm{Y}$ \\
\hline 31 & 0.36 & $\mathrm{Y}$ & $\mathrm{Y}$ & $\mathrm{Y}$ & 0.23 & $\mathrm{Y}$ & $\mathrm{Y}$ & $Y$ \\
\hline
\end{tabular}

\section{Conclusions}

Our present study investigated that TC and OTC residue level in honey samples available in the Iranian market. The recent study employed the HPLC method to simultaneous analysis of TC and OTC level in honey product. An optimization step was employed for the simple and SPE extraction procedure to decrease the amount of used solvents, samples, and the time consumed in the extraction stage, and reliable method to determine TC and OTC residue level in honey samples. A total of 31 samples in current study were examined and all selected samples had mean concentration of TC and OTC 
higher than MRL, suggesting the serious health problems in Iranian honey samples. Although, the preliminary work in the first step by antibiotic kits and separation of positive samples (31 sample). Finally, 31 positive samples were identified to investigate the residue level of TC and OTC in honey samples by the modified method. It seems that surveillance programs are required to monitor TC and OTC level in honey samples and their gradients in Iran. Therefore, it suggested application of this method in control laboratories and import-export inspection sites as alternative methods. It is necessary to comprehensively investigate the presence of antibiotics in food products. In this regard, it is essential to establish and enforce strict rules to minimize the contamination to the least possible amount and to prevent its adverse effects. Moreover, it is needed to properly assess other sources and to compare with other methods for stimulation of OTC and TC in food stuff such as milk, honey and so on.

\section{References}

Anderson, CR., Rupp, HS., Wu, W-H. (2005). Complexities in tetracycline analysis-chemistry, matrix extraction, cleanup, and liquid chromatography. Journal of Chromatography A ,1075,23-32.

Arabsorkhi, B., Sereshti, H.(2018). Determination of tetracycline and cefotaxime residues in honey by micro-solid phase extraction based on electrospun nanofibers coupled with HPLC Microchemical Journal,140,241-247.

Brasse, D. (2001). Stellungnahme der BBA zum Streptomycin-problem. Teil ,2, 24-25.

Carrasco-Pancorbo, A., Casado-Terrones, S., Segura-Carretero, A., Fernández-Gutiérrez, A.(2008). Reversed-phase high-performance liquid chromatography coupled to ultraviolet and electrospray time-of-flight mass spectrometry on-line detection for the separation of eight tetracyclines in honey samples. Journal of Chromatography A 1195:107-116.

Chen, T., Deng, W., Lu, W., Chen, R., Rao, P. (2001). Detection of residual antibiotics in honey with capillary electrophoresis. Chinese journal of chromatography, 19,91-93

Comission E (2002) 2002/657/EC: Commission Decision of 12 August 2002 Implementing
Council Directive 96/23/EC Concerning the Performance of Analytical Methods and the Interpretation of Results Official $\mathrm{J}$ of the European Communities.

Debayle, D., Dessalces, G., Grenier-Loustalot, MF.(2008).Multi-residue analysis of traces of pesticides and antibiotics in honey by HPLCMS-MS Analytical and Bioanalytical Chemistry 391:1011-1020

Dinkov, D., Kanelov, I., Zhelyazkova, I., Vashin, I.(2005). Persistence of tetracycline and oxytetracycline in bee honey after improper application on bee families. Bulgarian Journal of Veterinary Medicine, 8,205-209.

Fujita, KIH., Ishihara, M., Inukai. S., Tanaka, H., Taniguchi, M. (2008). Analysis of trace residues of tetracyclines in dark-colored honeys by highperformance liquid chromatography using polymeric cartridge and metal chelate affinity chromatography. Shokuhin Eiseigaku Zasshi ,49,196-203.

Giannetti, L., Longo, F., Buiarelli, F., Russo, MV., Neri ,B.(2010). Tetracycline residues in royal jelly and honey by liquid chromatography tandem mass spectrometry: validation study according to Commission Decision 2002/657/EC Analytical and bioanalytical chemistry,398,1017-1023

Granja, R., Nio, AM., Zucchetti, R., Nio, RM., Patel, R., Salerno, AG. (2009). Determination of erythromycin and tylosin residues in honey by LC/MS/MS Journal of AOAC International ,92,975-980

Hakuta, T., Shinzawa, H., Ozaki, Y.(2009).Practical method for the detection of tetracyclines in honey by HPLC and derivative UV-Vis spectra Analytical Sciences, 25,1149-1153

Jeon, M., Paeng, IR. (2008). Quantitative detection of tetracycline residues in honey by a simple sensitive immunoassay analytica chimica acta,626,180-185

Kalal, HS., Mahani, MK., Maragheh, MG., Chaloosi, M.(2007). HPLC determination of furfural after preliminary extraction to aqueous phase. Journal of liquid chromatography \& related technologies, 30,2081-2093

Khosrokhavar, R., Hosseini, M-J., Amini, M., PiraliHamedani, M., Ghazi-Khansari, M., Bakhtiarian, A.(2008). Validation of an analytical methodology for determination of oxytetracycline residue in milk by HPLC with 
UV detection. Toxicology mechanisms and methods , 18, 351-354

Khosrokhavar, R., Hosseini, M-J., Shoeibi, S., Jannat, B. (2011). Detection of oxytetracycline residuein infant formulaby high-performance liquid chromatography) HPLC. Iranian journal of pharmaceutical research: IJPR, 10,221

Mahmoudi, R., Moosavy, M., Norian, R., Kazemi, S., Asadi, NMR., Mardani, K. (2014) .Detection of oxytetracycline residues in honey samples using ELISA and HPLC methods.Pharmaceutical Sciences, 19 ,4,145150.

Martel, A-C., Zeggane, S., Drajnudel, P., Faucon, JP., Aubert, M.(2006) .Tetracycline residues in honey after hive treatment. Food additives and contaminants, 23,265-273

Münstedt, T., Rademacher, E., Petz, M. HPLC, Charm II and ELISA: advantages and disadvantages for the analysis of tetracyclines in honey. In: International Symposium APIMONDIA. Preventing Residues in Honey, Celle, 2002. vol 11.

Oka. H., Ikai, Y., Kawamura, N., Uno, K., Yamada, M., Harada, K-I., Suzuki, M. (1987) Improvement of chemical analysis of antibiotics: XII. Simultaneous analysis of seven tetracyclines in honey Journal of Chromatography A,400,253-261

Oka, H., Ito, Y., Matsumoto, H, (2000). Chromatographic analysis of tetracycline antibiotics in foods Journal of Chromatography A, 882,109-133

Pastor-Navarro, N., Morais, S., Maquieira, A., Puchades, R. (2007). Synthesis of haptens and development of a sensitive immunoassay for tetracycline residues: Application to honey samples. Analytica Chimica Acta ,594,211-218

Pena, A., Pelantova, N., Lino, C., Silveira, M., Solich, P. (2005). Validation of an analytical methodology for determination of oxytetracycline and tetracycline residues in honey by HPLC with fluorescence detection Journal of agricultural and food chemistry, 53,3784-3788

Peres, GT., Rath, S., Reyes, FGR. (2010). A HPLC with fluorescence detection method for the determination of tetracyclines residues and evaluation of their stability in honey. Food Control, 21,620-625

Saridaki-Papakonstadinou, M., Andredakis, S., Burriel, A., Tsachev, I. (2006). Determination of tetracycline residues in Greek honey Trakia Journal of Sciences, 4,33-36

Solomon, RJ., Santhi, VS., Jayaraj, V. (2006). Prevalence of antibiotics in nectar and honey in South Tamilnadu, India. Integrative Biosciences, 10,163-167

Thompson, HM. et al. (2005). Effects of European foulbrood treatment regime on oxytetracycline levels in honey extracted from treated honeybee (Apis mellifera) colonies and toxicity to brood Food additives and contaminants 22:573-578

Tsukamoto, T., Yasuma, M., Yamamoto, A., Hirayama, K., Kihou, T., Kodama, S., Inoue, Y. (2009). Evaluation of sulfobetaine-type polymer resin as an SPE adsorbent in the analysis of trace tetracycline antibiotics in honey Journal of separation science ,32,3591-3595

Viña, P., Balsalobre, N., López-Erroz, C., Hernández-Córdoba, M. (2004). Liquid chromatography with ultraviolet absorbance detection for the analysis of tetracycline residues in honey Journal of Chromatography $A$ ,1022,125-129

Wan, G-H., Cui, H., Zheng, H-S., Zhou, J., Liu, L-J., $\mathrm{Yu}, \mathrm{X}-\mathrm{F}$. (2005). Determination of tetracyclines residues in honey using high-performance liquid chromatography with potassium permanganatesodium sulfite- $\beta$-cyclodextrin chemiluminescence detection Journal of Chromatography $B$,824,57-64. 